\title{
RELAÇÃO ENTRE A INFILTRAÇÃO DA ÁGUA NOS SOLOS E A ESTABILIDADE DOS AGREGADOS EM SISTEMAS DE MANEJOS DIFERENTES NA BACIA HIDROGRÁFICA DO RIO SÃO ROMÃO - NOVA FRIBURGO / RJ
}

\author{
Raphael Rodrigues Brizzi \\ Instituto Federal de Educação, Ciência e Tecnologia do Rio de Janeiro - IFRJ, Programa de Pós-Graduação em \\ Ciências Ambientais em Áreas Costeiras, Arraial do Cabo, RJ, Brasil. \\ raphael.brizzi@ifrj.edu.br \\ Andréa Paula de Souza \\ Faculdade de Educação da Baixada Fluminense - FEBF/UERJ, Instituto de Geografia, Duque de Caxias, RJ, \\ Brasil \\ andreaps.uerj@gmail.com \\ Alexander Josef Sá Tobias da Costa \\ Universidade do Estado do Rio de Janeiro - UERJ, Programa de Pós-Graduação em Geografia, Rio de Janeiro, \\ RJ, Brasil \\ ajcostageo@gmail.com
}

\begin{abstract}
RESUMO
O avanço das áreas de pastagem e da agricultura sobre a Mata Atlântica, e seu manejo inadequado, cada vez mais colabora para a erosão dos solos na Área de Proteção Ambiental Estadual de Macaé de Cima, em Nova Friburgo - RJ. O estudo em questão visa à compreensão dos processos erosivos em diferentes tipos de usos do solo, tais como floresta, pastagem e cultivo. Para tal, foi avaliada a infiltração da água nos solos, o DMP, DMG, IEA - Índices de Estabilidade dos Agregados e a influência do carbono orgânico na agregação, na profundidade de $0-10 \mathrm{~cm}$. Os resultados mostraram que a floresta apresentou o maior volume de água infiltrado, seguido do cultivo e da pastagem, respectivamente. Os parâmetros de agregação do solo foram influenciados pelos altos valores de carbono orgânico que resultou em um alto valor delEA. Na avaliação dos dois experimentos, pode-se dizer que há uma relação direta dos dados de infiltração com a estabilidade dos agregados, observando-se a seguinte ordem de suscetibilidade à erosão: pastagem >cultivo> floresta . Conclui-se, portanto, que o uso florestal é mais adequado para uma maior absorção da água na bacia hidrográfica, reduzindo o tempo de chegada no canal principal e a intensidade dos processos erosivos nas encostas.
\end{abstract}

Palavras-chave: Uso do solo. Erosão. Propriedades físico-hídricas. Unidades de Conservação.

\section{RELATIONSHIP BETWEEN WATER INFILTRATION IN SOILS AND THE STABILITY OF AGGREGATES IN DIFFERENT MANAGEMENT SYSTEMS IN BASIN OF SAO ROMAO RIVER - NOVA FRIBURGO / RJ}

\begin{abstract}
The pasture and agriculture areas advancement on the Atlantic Forest, and its inadequate management, contributes increasingly to soil erosion in the Environmental Protection Area of Macaé de Cima, in Nova Friburgo - Rio de Janeiro. The study aims to understand the erosive processes in different types of soil uses, such as forest, pasture and cultivation. For that, water infiltration in the soils, the DMP, DMG, IEA and the influence of the organic carbon in the aggregation were evaluated in a depth of $0-10 \mathrm{~cm}$. The results showed that the forest presented the largest volume of infiltrated water, followed by cultivation and pasture, respectively. Soil aggregation parameters were influenced by the high values of organic carbon resulting in high value. In the evaluation of the two experiments, it can be said that there is a direct relation of the infiltration data with the stability of the aggregates, where it is noticed the following order of susceptibility to erosion: pasture > cultivation > forest.
\end{abstract}


Therefore, it is conclusive that the forest use is more proper for a greater absorption of water in the river basin, reducing the time of arrival in the main channel and the intensity of the erosive processes in the slopes.

Keywords: Land use. Infiltration. Aggregate stability. Erosion, Protected Areas.

\section{INTRODUÇÃO}

A mudança da paisagem tem sido alvo de diversas discussões, principalmente quando associada ao recorte espacial de bacias hidrográficas em unidades de conservação. Esta categoria, seguida destes recortes espaciais, tem sido afetada constantemente com a mudança do uso do solo, gerando alterações incalculáveis no fluxo de energia e matéria nos geossistemas.

No Brasil, o avanço dos sistemas agropastoris tem causado a redução sistemática do bioma Mata Atlântica, alterando o micro clima, gerando diversas alterações físicas, químicas e biológicas nos solos e mudando a dinâmica hidrológica dos sistemas avaliados. Embora o código florestal brasileiro tenha uma das legislações mais completas do mundo (ICMBio, 2017a), essas alterações ainda são justificadas pela ausência e/ou fragilidade da própria legislação frente às causas ambientais em unidades de conservação.

Como consequência dessas alterações pela mudança do uso do solo e pelo manejo a que os solos são submetidos, têm-se a sua degradação como um dos parâmetros de qualidade ambiental mais estudado na avaliação de geossistemas, caracterizado, principalmente, pelo aparecimento de sulcos, ravinas e voçorocas nas encostas, além da perda da fertilidade.

Nessa linha de raciocínio, tem-se a região da Serra do Mar como domínio geomorfológico de grande extensão no Estado do Rio de Janeiro, abrigando o maior corredor biológico de Mata Atlântica. Tal região é, ainda, considerada como um dos Hot Spots mundiais na conservação da biodiversidade ( MYERS, 1988), sendo submetido a diversos tipos de uso e ocupação do solo. Segundo Ab'Saber (2003, p.17), essas áreas estão inseridas nos domínios morfodinâmicos de "Mares de Morros", e "tem mostrado ser o meio físico, ecológico e paisagístico mais complexo e difícil do país em relação as ações antrópicas". O mesmo autor, afirma, ainda, que se trata da "região sujeita aos mais fortes processos de erosão e movimentos coletivos de solos em todo o território brasileiro" (AB'SABER, 2003, p.17). Sendo assim, a falta de planejamento e gerenciamento do uso do solo caracteriza como ineficaz a ocupação humana nessas áreas. Estudos realizados por Silva et al. (2012) na sub-bacia hidrográfica do rio São Pedro (médio e baixo curso da bacia do rio Macaé), na região Serrana do Estado do Rio de Janeiro, concluíram, através do monitoramento de imagens de satélites, que as áreas agrícolas e de pastagens estão avançando e, consequentemente, resultando no aumento do desmatamento.

Dentro dessas áreas agropastoris, Lima et al. (2008) e Neves et al. (2011) constataram não somente que os solos são altamente suscetíveis à erosão, mas também que a classificação textural dos pontos avaliados variam de franco, franco-argilo-arenoso à franco-arenoso. Entretanto, os autores não avaliaram a suscetibilidade dos solos à erosão por classe de solos, mas sim, de modo aleatório em toda a bacia hidrográfica.

Brizzi et al. (2017) também apontaram alterações na paisagem do alto curso da bacia do rio Macaé, onde 0 avanço das áreas agropastoris e loteamentos, associadas as altas declividades, alteram as propriedades físicas, químicas e biológicas dos solos e favorecem o desenvolvimento de ravinas e voçorocas nas encostas.

Nessa perspectiva, diversos trabalhos de diagnóstico de áreas degradadas, em especial aqueles associados às propriedades físicas e químicas dos solos, foram relatados para a bacia hidrográfica do rio Macaé. Não obstante, os trabalhos citados não correlacionam erosão com o comportamento da água nos solos. Esta visão não invalida as pesquisas, mas impossibilita a compreensão dos processos erosivos em sua plenitude, sobretudo por se tratar de erosão em um país tropical e de regimes pluviométricos concentrados.

Assim, acredita-se que o uso e o manejo dos solos destinado a essas áreas alteram a sua estrutura de formas distintas, impactando diretamente as taxas de infiltração e, consequentemente, o volume

$\begin{array}{llllll}\text { Caminhos de Geografia } & \text { Uberlândia - MG } & \text { v. 19, n. } 67 & \text { Set/2018 } & \text { p. 304-321 Página } 305\end{array}$


de água absorvido , . Com isso, os solos se tornamaltamente suscetíveis à erosão, sobretudo quando junto com outras propriedades físicas, químicas e biológicas, deixando os agregados dos solos instáveis e vulneráveis à erosão laminar.

Sendo assim, buscou-se estudar esses fenômenos na sub-bacia do Rio São Romão, em Nova Friburgo - RJ, inserida na Área de Proteção Ambiental Estadual de Macaé de Cima, visando compreender as relações entre os processos erosivos em diferentes usos do solo. Dito de outro modo, objetivou-se entender a degradação, a partir da investigação das propriedades físico-hídricas do solo, através de experimentos de campo e laboratório, com vistas a subsidiar estudos futuros de modelagem hidrológica.

\section{PROCESSOS EROSIVOS NAS ENCOSTAS}

A erosão dos solos pode ser definida como o processo de retirada (detachment) das partículas do solo presentes nas partes mais íngremes (geralmente à montante das encostas), mas que são transportadas e depositadas nas partes mais suavizadas do relevo (geralmente à jusante das encostas), pela ação de agentes como a água, o vento e o gelo (MORGAN, 1986;; GUERRA, 2009a; 2009c; BERTONI e LOMBARDI NETO, 2010).

A suscetibilidade dos solos à erosão é determinada por fatores controladores, como, por exemplo, a erosividade da chuva, as propriedades do solo, a cobertura vegetal, a característica das encostas, o tipo de uso e o manejo destinado ao solo (GUERRA, 2009a; BERTONI e LOMBARDI NETO, 2010).

Assim, o início do processo erosivo é caracterizado pelo efeito splash, que, com a energia cinética da chuva associado ao diâmetro da gota d'água, desagrega as partículas do solo,, promovendo o entupimento dos poros menores ao seu redor e dificultando o processo de infiltração. Em seguida, inicia-se o processo de selamento da superfície e a possível formação de poças (puddle) de água, que dariam início ao escoamento superficial - runoff (Figura 1) (MORGAN, 1986; GUERRA, 2009a; 2009c).

Figura 1: Efeito splash provocando o início do processo erosivo nas encostas
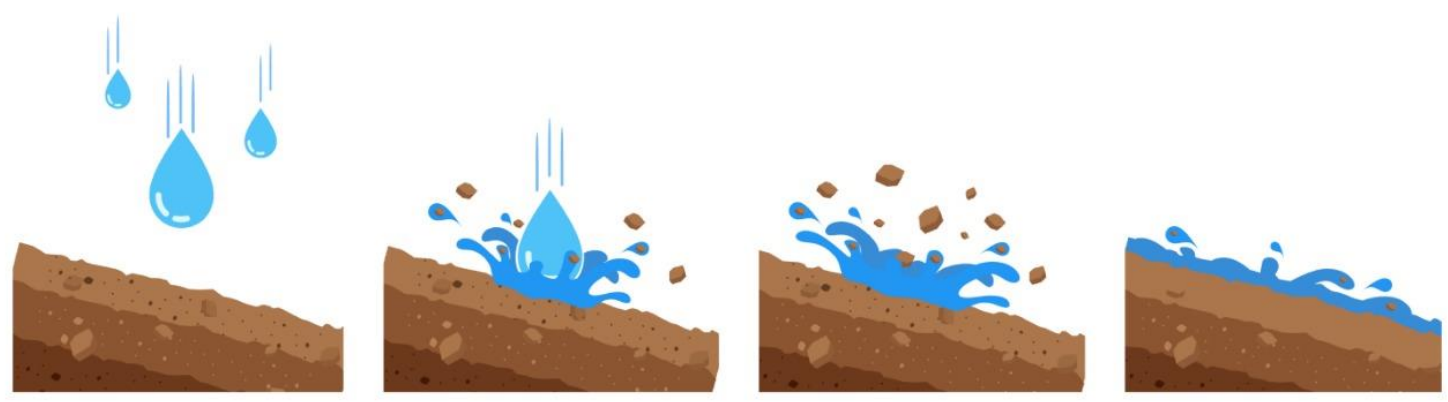

Fonte: Autor (2018).

Ressalta-se que o selamento da parte superficial do solo não necessariamente está ligado a saturação do solo como um todo. Esse processo está intimamente ligado a uma dinâmica física que influencia diretamente na percolação da água no solo, como, por exemplo, o nível de compactação ao qual o solo foi submetido, assim como o arranjamento das partículas, a mudança abrupta da textura em perfil e o índice de micro e macroporosidade do solo.

Horton (1945), ao falar sobre o runoff, chama a atenção para a resistividade do solo. Ou seja, a capacidade que os solos têm de resistir à intensidade e ao volume de chuva, por um período de tempo, que geralmente é medido em minutos. Se a força de cisalhamento do material for excedida por esses fatores, consequentemente acarretará em um processo erosivo. Como pode ser visualizado abaixo, na figura 2, o fluxo superficial (overland flow) tende a se concentrar e ganhar mais energia na

$\begin{array}{llllll}\text { Caminhos de Geografia } & \text { Uberlândia - MG } & \text { v. 19, n. } 67 & \text { Set/2018 } & \text { p. 304-321 } & \text { Página } 306\end{array}$


média encosta. Assim, o potencial erosivo aumenta e carrega o material menos resistente para a jusante das encostas e para as calhas fluviais, formando solos transportados e depósitos em rios, conhecidos como coluvionares e aluvionares, respectivamente.

Figura 2: Perfil de encosta mostrando o processo de erosão no solo através do escoamento superficial.

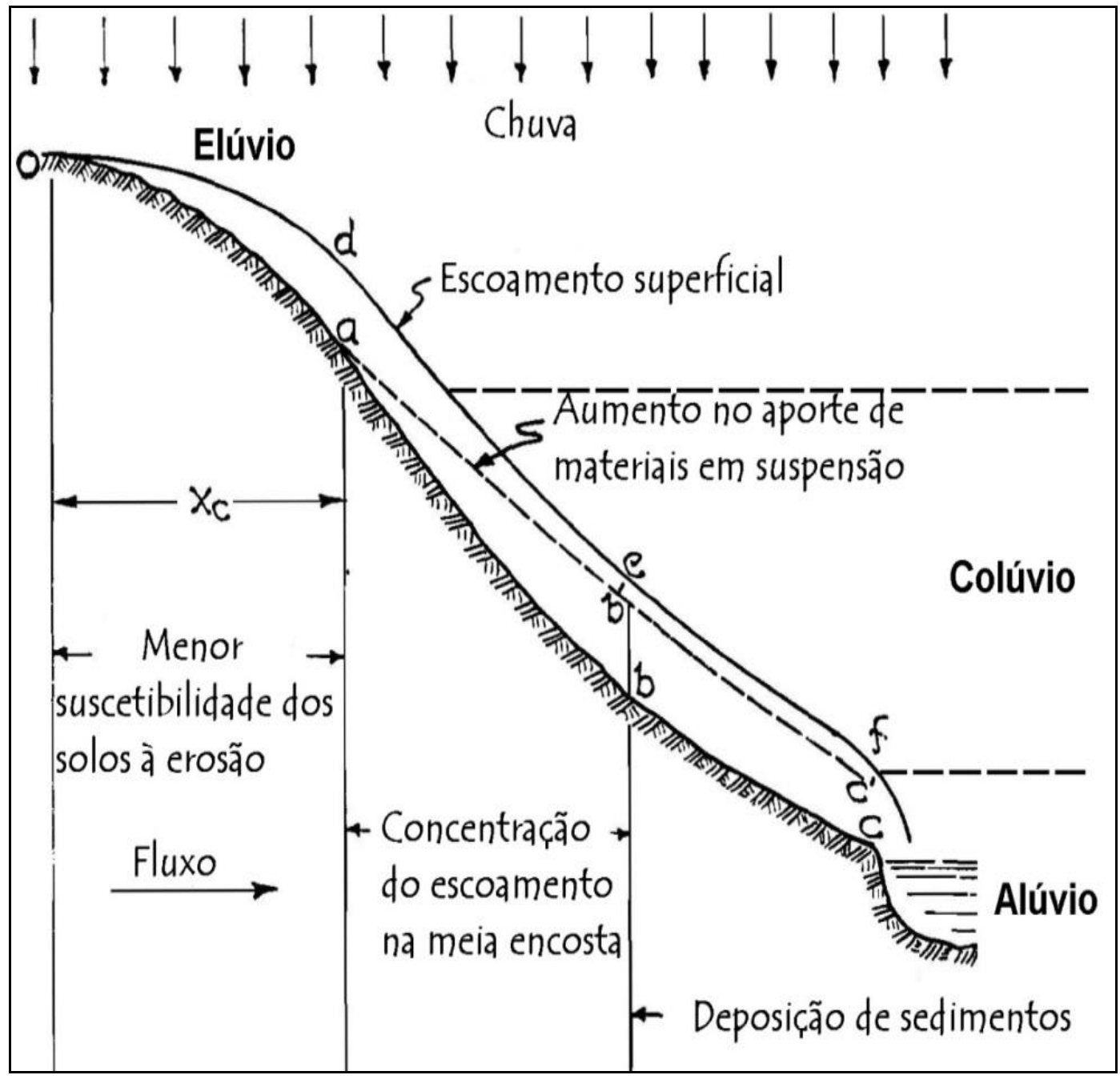

Fonte: Adaptado de Horton (1945, p.316).

Como consequência, pode-se visualizar o surgimento de cicatrizes na paisagem, como sulcos, ravinas e voçorocas (figuras 3 e 4), que podem ser agravados, caso não sejam tomadas medidas conservacionistas eficazes. Os custos para recuperação dessas feições são onerosos, afastando o interesse do poder público e até mesmo dos donos de terra na recuperação dessas áreas, salvo quando apresentam prejuízos consideráveis a esses últimos, como perda excessiva do gado, destruição de moradias, óbitos ou a perda de fertilidade dos solos para a produção de alimentos. Além disso, a mudança da paisagem torna-se menos atrativa em regiões com forte potencial turístico e prejudicial para as famílias que dele vivem. 
Figura 3: Relevo dissecado pelo pisoteio do gado e pequenos movimentos de massa na comunidade de São Romão - Nova Friburgo/RJ.

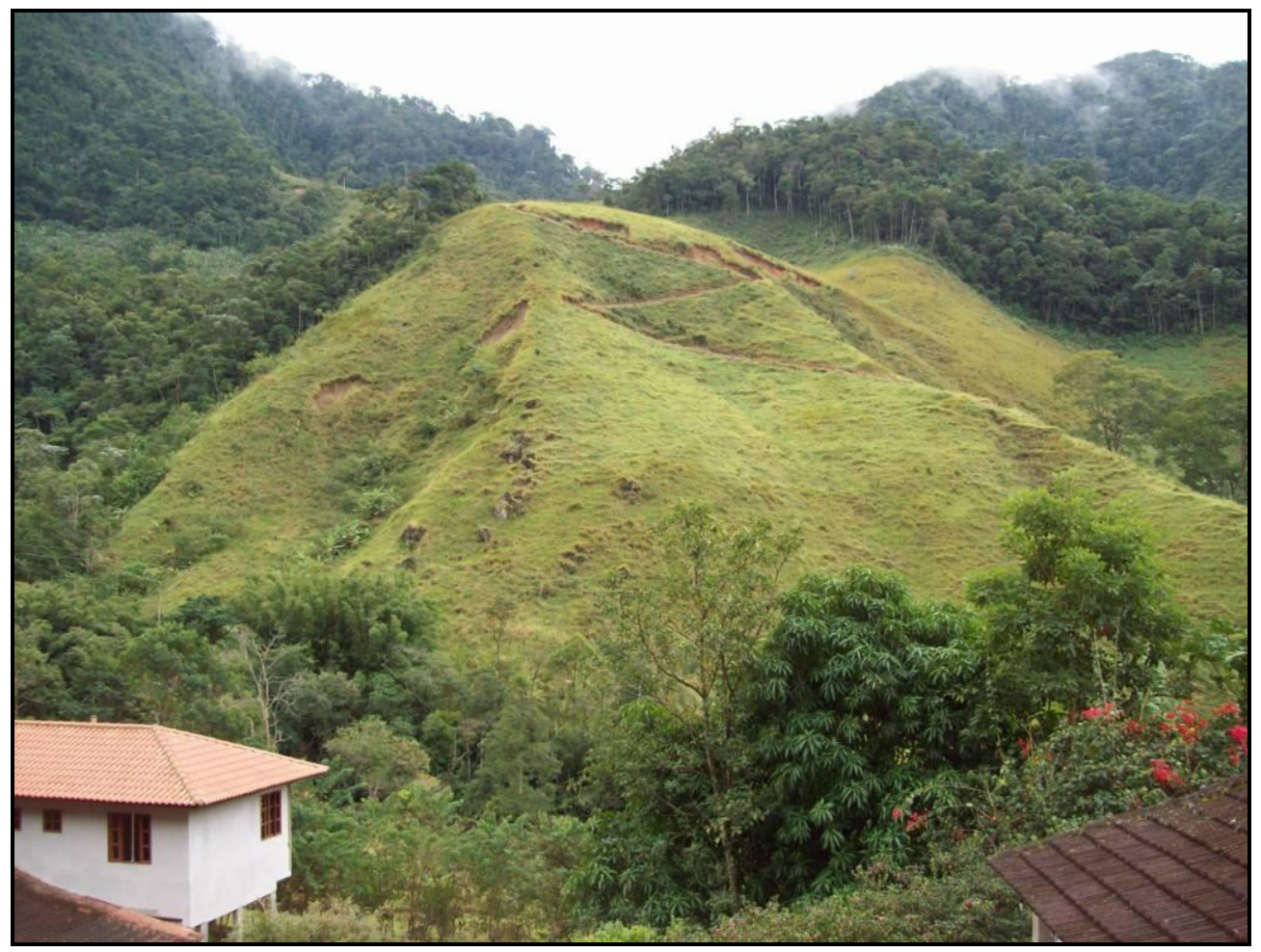

Fonte: Autor (2018).

Figura 4: Voçoroca em uma encosta côncava no sopé do Pico do Frade, em Glicério - Médio curso da bacia do rio Macaé /RJ.

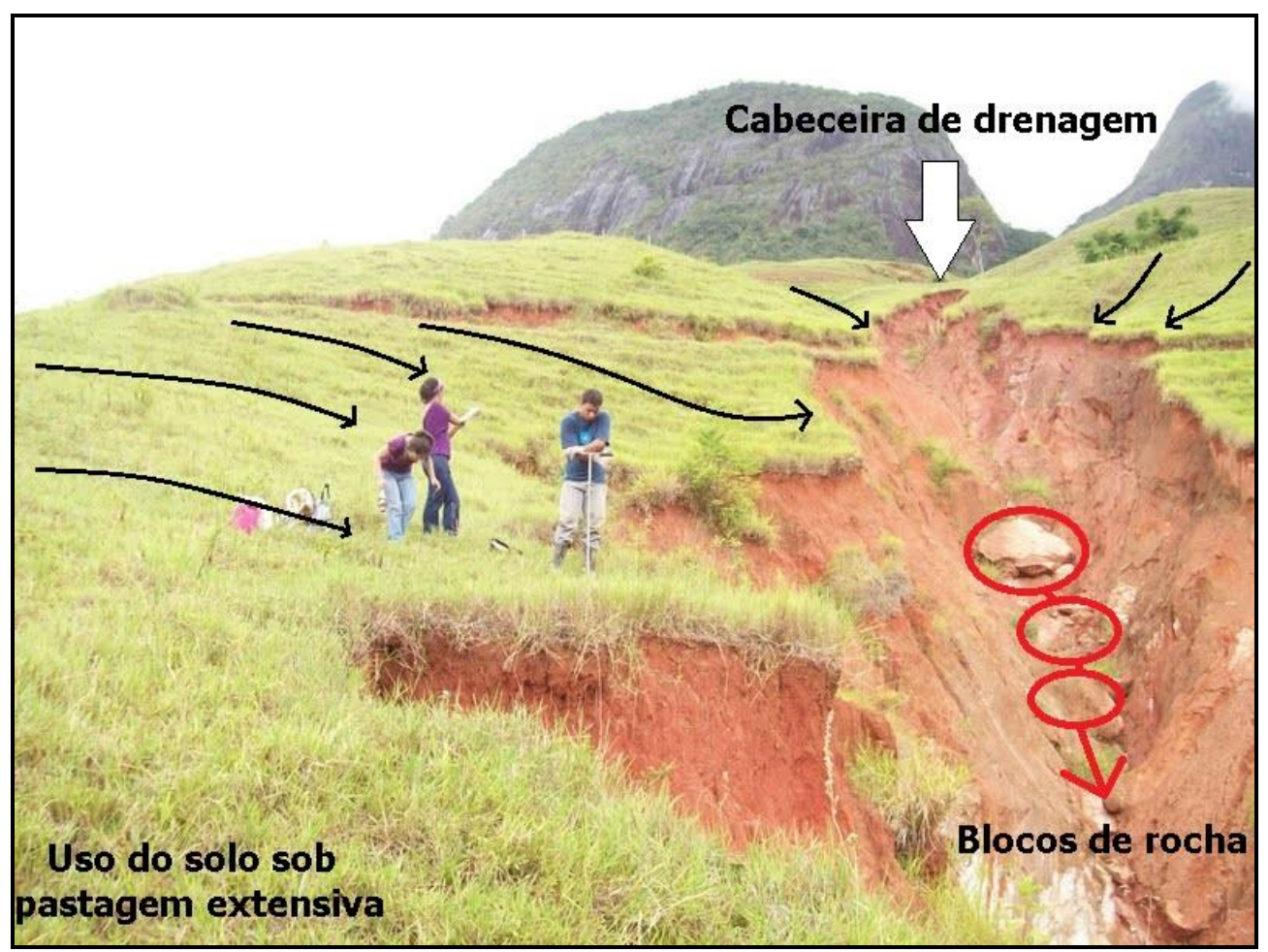

Fonte: Autor (2018). 
Ao tratarem de erosão hídrica, Formiga et al. (2012, p.101) salientam que "dos estudos hidrológicos, após a precipitação, a infiltração é o principal fenômeno relativo à geração do escoamento superficial'. Ainda acerca da inflitração, eles salientam ser fundamental sua compreensão, pois é ela que irá condicionar a formação de cicatrizes na paisagem como as ravinas e voçorocas. No entanto, é importante que se entenda que esses processos são dependentes das propriedades físicas e químicas dos solos, sendo esta combinação importante na formação do escoamento superficial e subsuperficial, assim como no abastecimento de aquíferos livres e confinados (MARTINS, 1978; SOUSA PINTO, 1978).

Para melhor compreensão da infiltração é importante entender os processos físicos ocorridos dentro do solo. Existem duas forças que controlam o processo de infiltração, a saber: a gravitacional e a capilar (BRADY, 1989; REICHARDT e TIM, 2012). A primeira diz respeito à força da gravidade, que, no caso da direção da infiltração ser vertical, comumente encontrada em solos saturados, resultam em uma poro-pressão positiva (HILLEL, 1970). A segunda é mais comum em solos não saturados, onde a direção da força pode ocorrer não só em função da gravidade, mas também em função das forças de adesão e coesão, podendo agir também lateralmente, o que resulta em uma poro-pressão negativa (HILLEL, 1970). É de suma importância a compreensão desses processos, visto que estes estão atrelados à capacidade de infiltração da água nos solos, em função da intensidade da chuva por um período de tempo.

Hillel (1970), ao estudar o potencial da água em solos saturados e não saturados, acrescenta que,

o potencial de pressão da água no solo pode ser tanto positivo quanto negativo. Sempre que a pressão hidrostática da água do solo for superior à pressão atmosférica, considera-se o potencial de pressão como positivo. Quando a água do solo estiver a uma pressão hidrostática menor do que a da atmosférica (um estado de sub-pressão geralmente conhecido como tensão ou sucção) o potencial de pressão é considerado como negativo (HILLEL, 1970, p. 59).

Outro fator que influencia diretamente na infiltração, e na posterior percolação da água no solo, é a umidade que antecede um evento chuvoso e a evapotranspiração da fauna endopedônica (REICHARDT e TIMM, 2012), que controla a quantidade de água e a maneira pela qual caracterizará a percolação da água no perfil.

Dialogando com a essa discussão,, o modelo de Horton (1940, apud FORMIGA et al., 2012) mostra que a capacidade de infiltração, por um período de tempo, tende a diminuir até que se chegue a um valor estável, uma constante. Nesse caso, o autor considera que os fenômenos que acontecem na superfície do solo são mais importantes do que no processo de percolação da água dentro do perfil, onde o encrostamento superficial, a expansão e a contração do solo, assim como sua compactação, acabam por justificar sua teoria/modelo. Na contrapartida dessa visão, , Medina (1972) afirma que a estabilização do movimento da água no solo é sensivelmente influenciada pela textura, estrutura, profundidade, uniformidade, camadas impermeáveis, proximidade com o lençol freático e temperatura, sendo esses parâmetros mais associados à água subsuperfícial.

De forma generalizada, é comum que as áreas de pasto e de cultivo apresentem os menores índices de infiltração, devido, especialmente, à diminuição da porosidade dos solos em detrimento do manejo inadequado. Tal manejo inadequado envolve as áreas de pasto marcadas pelo pisoteio do gado e as áreas de cultivo (principalmente no plantio convencional) afetadas pelo maquinário utilizado. Já as áreas de floresta, geralmente, servem como padrão para os demais usos, visto que as propriedades físicas do solo (textura, estrutura, porosidade, estabilidade dos agregados, entre outros) são menos alteradas, o que facilita a passagem da água no perfil, tendo, ainda, como colaborador, a fauna endopedônica e o sistema radicular encontrado.

Nessa perspectiva, a estabilidade dos agregados é uma resposta na mudança da estrutura às quais os solos foram submetidos pelo uso sobrejacente. Deste modo, uma maior infiltração é resultante de solos com boa estrutura. Por outro lado, uma baixa infiltração indica que os solos foram alterados, o que caracteriza baixa estabilidade dos agregados em relação aos solos nãotransformados.

\section{ÁREA DE ESTUDO}

A sub-bacia do rio São Romão (figura 5), com aproximadamente $21,23 \mathrm{~km}^{2}$, faz parte da bacia hidrográfica do Rio Macaé, e está localizada no Município de Nova Friburgo - RJ, sendo limitada pelas coordenadas $7529098,685664 \mathrm{~N}, 7525490,168798 \mathrm{~S}, 786152,834975 \mathrm{E}$, 780996,959470W.

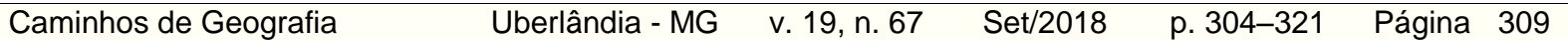


Além de estar localizada em um dos municípios com maior área de Mata Atlântica preservada do Estado, na região serrana do Estado do Rio de Janeiro, apresenta uma RPPN (Reserva Particular do Patrimônio Natural), com 54,02 há (ICMBIo, 2017b), tornando-se interessante a preservação não só da RPPN, mas também da sub-bacia como um todo, pois está completamente inserida na Área de Proteção Ambiental Estadual de Macaé de Cima.

Figura 5: Mapa da sub-bacia hidrográfica do rio São Romão (BHRSR) - Nova Friburgo / RJ, com destaque para os pontos de coleta em diferentes usos do solo.

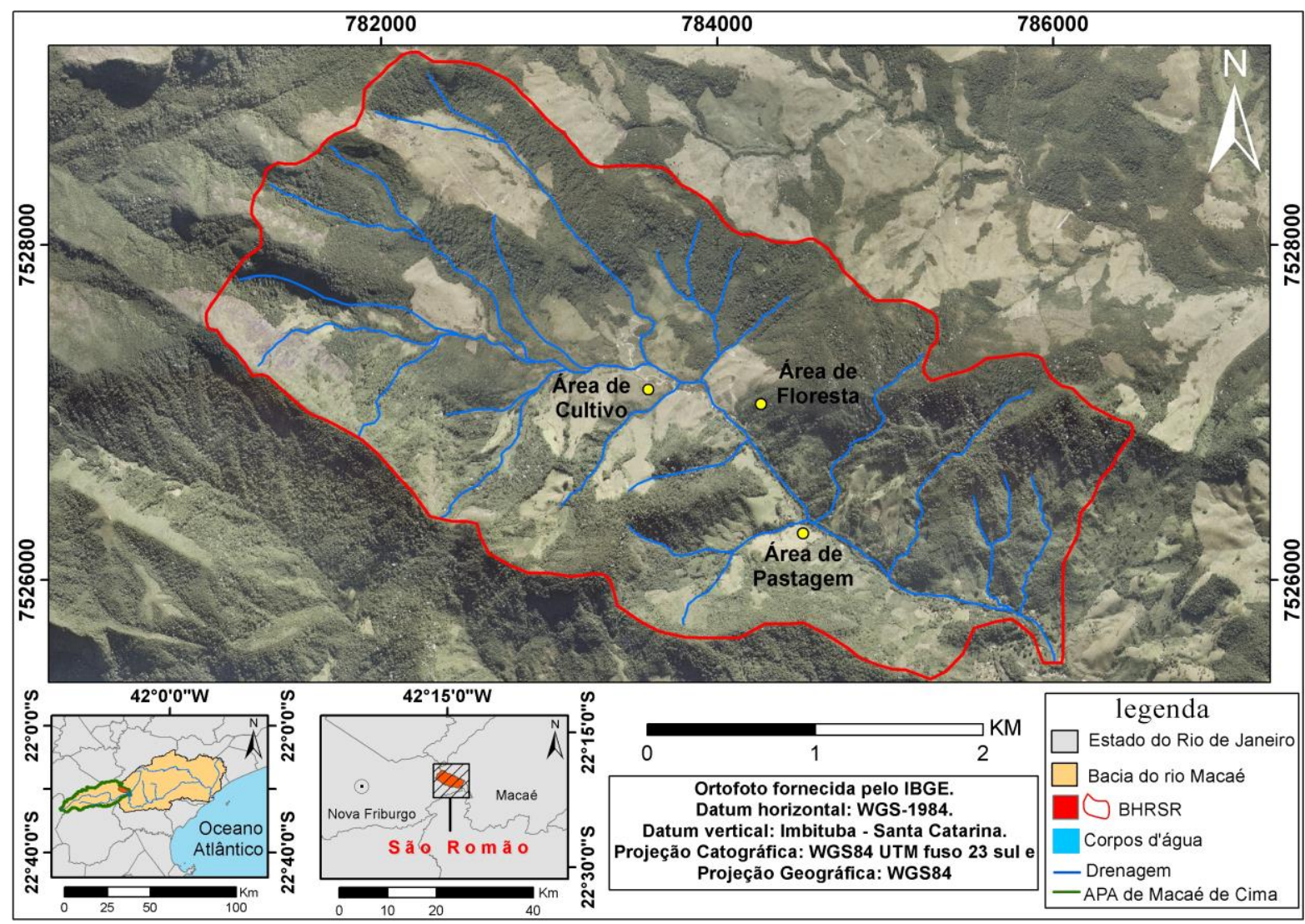

Fonte: Autor (2018).

Segundo Mendes (2010), o quadro favorável de conservação da região de Macaé de Cima, na qual a sub-bacia do rio São Romão está inserida, é fruto do seu processo histórico de ocupação. Segundo a autora, a bacia do rio Macaé, no século XIX e início do século XX, foi intensamente marcada pela monocultura do café, quedestruiu grande parte da Mata Atlântica da região. Todavia, diferentemente do que aconteceu com os demais remanescentes de Mata Atlântica, o uso da floresta fora também substituído pela pastagem.A Área de Proteção Ambiental de Macaé de Cima, por exemplo, foi marcada majoritariamente por culturas de subsistência, como a da banana, do inhame e da mandioca.

Quanto à classificação da vegetação encontrada na região, a sub-bacia hidrográfica está inserida no domínio de Floresta Ombrófila Densa Montana, situada entre as cotas de 500 a 1500 metros de altitude, cuja estrutura é mantida principalmente próxima ao cume dos relevos dissecados (INEA, 2011).

A área é ocupada, predominantemente, por produtores rurais, em que o cultivo de bananeiras, eucalipto e açaí, se destaca . Estes cultivos estão atrelados, principalmente, à agricultura de subsistência, tendo o cultivo de bananeiras, o uso de pastagens e a fragmentação florestal, maior expressividade da paisagem (figura 6 ). 
Figura 6: Distribuição de diferentes tipos de uso do solo na bacia hidrográfica do rio São Romão Nova Friburgo/RJ.

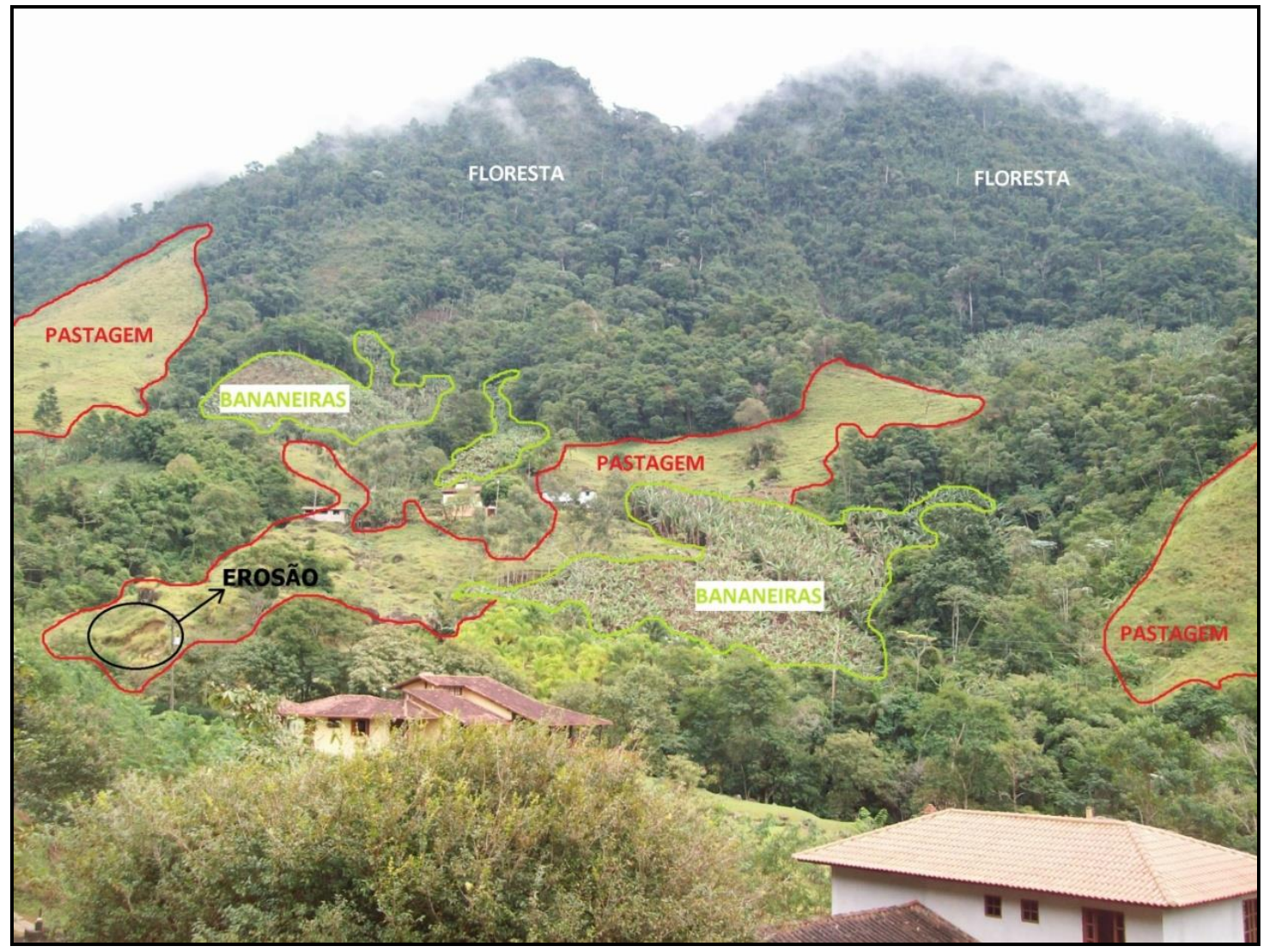

Fonte: Autor (2018).

Segundo Freitas (2003), a utilização do cultivo de bananeiras é preocupante, principalmente quando relacionado às altas declividades, visto que a geometria da folha de bananeira corrobora para o fluxo de tronco, o que resulta na concentração do fluxo de água no solo.

O turismo é outro fator marcante dessa região. É uma opção para a geração de renda das famílias, sendo comum o aluguel de casas para as altas temporadas. Como marca da exploração do turismo, tem-se a pousada "Vila São Romão", que solicitou o enquadramento da área da pousada ao ICMBio, como Reserva Particular do Patrimônio Natural (RPPN), cujo objetivo é a conservação da biodiversidade do local (ICMBio, 2017b).. Entretanto, a comunidade de São Romão também é alvo de loteamentos e do manejo inadequado, o que pode vir a ter como resultado a mudança da paisagem e a influência no uso-cobertura da sub-bacia hidrográfica, devido à busca de maior contato com a natureza, sendo majoritariamente preservada no local.

Estudos realizados por Nascimento et al. (2010) apontam que os regimes pluviométricos da bacia do rio Macaé oscilam de acordo com o relevo, sendo que os maiores volumes de chuva concentram-se no alto curso, se comparado aos dados do médio e baixo curso da bacia. Tais estudos afirmam, ainda, que as grandes altitudes podem influenciar em invernos frescos e verões quentes ou brandos.

Em relação aos gráficos analisados por Nascimento et al. (2010), em detrimento das séries históricas das estações pluviométricas da Agência Nacional de águas (ANA), na bacia do rio Macaé, chegou-se à conclusão de que os verões estão cada vez mais chuvosos e os invernos cada vez mais secos, visto que o período de outubro a março corresponde aos meses mais chuvosos, enquanto que os meses de julho a agosto apresentam os meses mais secos.

Segundo Tornthwaite e Mather (1995 apud, MENDES, 2010), a classificação da região é do tipo Asuperúmido e B-mesotérmico, e é correspondente ao Cfb Koeppen. A temperatura média anual é de $17,9^{\circ} \mathrm{C}$, sendo o período de janeiro a março os meses mais quentes e de junho a agosto aqueles mais frios.

$\begin{array}{llllll}\text { Caminhos de Geografia } & \text { Uberlândia - MG } & \text { v. 19, n. } 67 & \text { Set/2018 } & \text { p. 304-321 Página } 311\end{array}$


A geologia encontrada na região de Macaé de Cima, segundo o projeto Radambrasil (BRASIL, 1983), é marcada pela presença de rochas intrusivas e metamórficas Pré-Cambrianas, inseridas na unidade litoestatigráfica do "complexo Paraíba do sul", sendo a maior parte dos compartimentos rochosos encontrados na região, compostos por granitos e gnaisses. A região na qual a sub-bacia está inserida também é marcada por intensas zonas de falhamento e possíveis movimentos tangenciais sobre as falhas principais (BRASIL, 1983).Segundo Dantas (2000), a geomorfologia da área de estudo encontra-se em relevo montanhoso e bastante acidentado, com predominância de vertentes retilíneas a côncavas, escarpadas e com topos levemente arredondados, inserida no domínio de 'Escarpas Serranas'. Essas características são um forte indicador para a grande ocorrência de erosão e movimentos de massa nessa região, como os que ocorreram em janeiro de 2010.

No mapa de solos de baixo reconhecimento da Embrapa (2003), na escala de 1:250.000, a sub-bacia do rio São Romão está inserida na classificação de "Cambissolos Háplicos Ta Eutróficos". Segundo Embrapa ( 2018), os Cambissolos podem apresentar variação quanto à sua profundidade, podendo ser rasos ou profundos, sendo majoritariamente, pedregosos, cascalhentos, ou, até mesmo, rochosos e, altamente, suscetíveis à erosão, quando presentes em áreas de alta declividade.

\section{MATERIAL E MÉTODOS}

Foram escolhidas três áreas de diferentes usos na bacia hidrográfica do rio São Romão: (1) floresta, (2) pastagem e (3) cultivo de açaí plantado no sentido das curvas de nível, em covas e na forma de fileiras, sem a presença de outros cultivos. Em cada um dos usos, foi medida a declividade, a umidade antecedente do solo ( 3 a 5 minutos antes do teste de infiltração), o teste de infiltração com o infiltrômetro de Hills e a coleta de amostra amolgada na profundidade de $0-10 \mathrm{~cm}$ para a avaliação da estabilidade dos agregados em água (figura 7).

Figura 7: Coletor de volumétrico de Uhland de $100 \mathrm{~cm}^{3}$ e verificação da umidade in situ $(\mathrm{A})$, realização do teste de infiltração (B) e coleta de amostra amolgada de solo na profundidade de $0-10 \mathrm{~cm}$ para análise de estabilidade dos agregados (C e D).

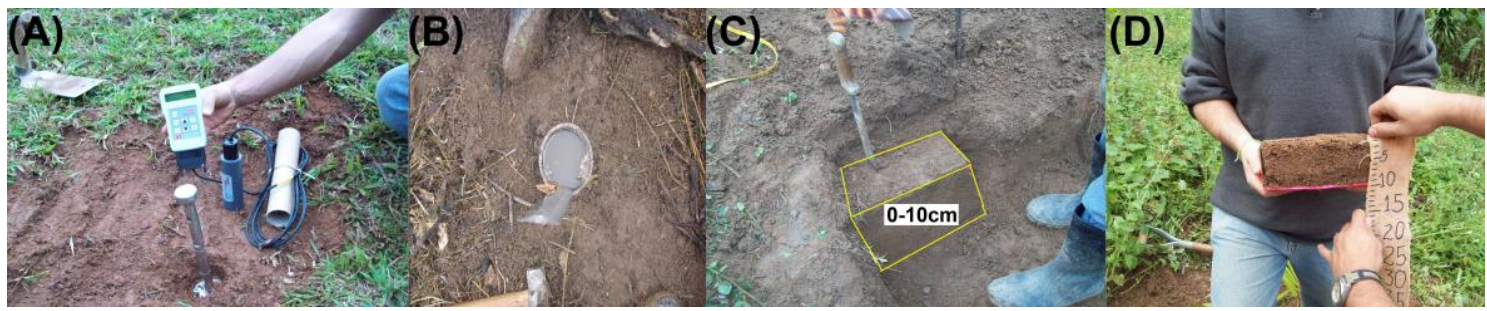

Fonte: Autor (2018).

A avaliação da umidade antecedente aos testes de infiltração foi realizada três vezes com um Theta Probe (DELTA-T DEVICES ML2X), numa área de 2x2 metros, em cada uso, para fins estatísticos.

O teste de infiltração seguiu a metodologia proposta por Guerra (2009b), onde foi utilizado um cilindro de $15 \mathrm{~cm}$ de altura $\times 10 \mathrm{~cm}$ de diâmetro. $O$ mesmo foi introduzido 5 centímetros no solo, com régua graduada, para avaliação da descida da água.

Para as análises de estabilidade dos agregados, seguiu-se a metodologia proposta por Yoder (1935) e adaptada por Castro Filho et al. (1988). Cada bloco de solo coletado possibilitou a realização de três repetições, possuindo cada repetição uma duplicata no conjunto de peneiras (figura 8, B e C). 
Figura 8: A - Destorroamento da amostra indeformada em peneira de 4 e $2 \mathrm{~mm}$; B - jogo de peneiras em sequência vertical; C - Vista azimutal do aparelho de estabilidade com o par do conjunto com 5 peneiras cada e; D - separação dos agregados após o tamiesamento.

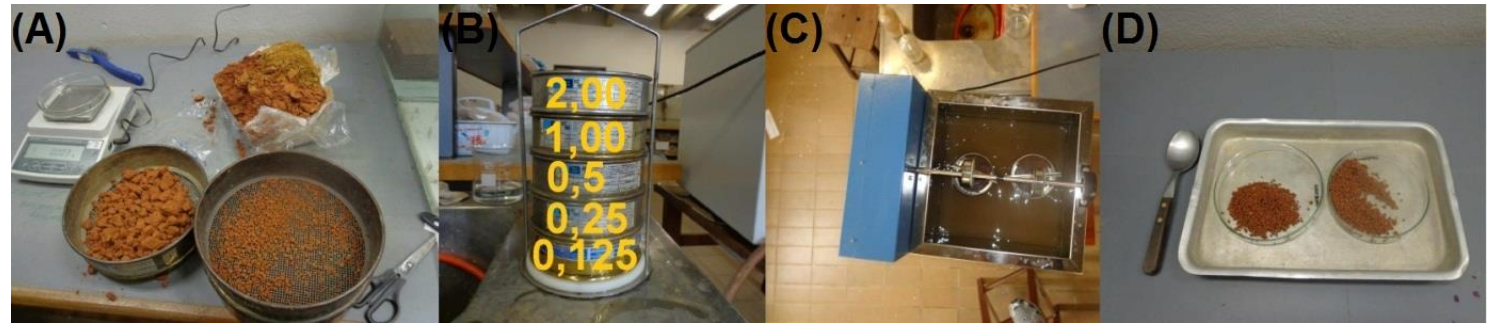

Fonte: Autor (2018).

Os blocos de solo coletados foram desagregados e homogeneizados em peneiras de $4 \mathrm{~mm}$ e $2 \mathrm{~mm}$ (figura 8a) antes do tamisamento úmido para ser determinada a distribuição das classes $(2,0-1,0-$ $0,5-0,25-0,125)$ de agregados por via úmida, utilizado no método de Yoder (CASTRO FILHO et al., 2002).

Cada amostra foi umedecida lentamente por duas horas e depois as mesmas foram transferidas para o aparelho de Yoder, com peneiras de malhas de 2,0, 1,0, 0,5, 0,25 e 0,125 mm de abertura.

As amostras oscilaram durante 15 minutos com, aproximadamente, 32 rotações por minuto. Após o término das oscilações, o conteúdo retido em cada uma das peneiras foi secado em estufa a 105으 $\mathrm{C}$ durante 24 horas.

Após a secagem, o material retido nas peneiras correspondentes (figura 8d), em duplicata, foi separado em sacos de papel e identificado para a realização das análises de carbono orgânico, segundo metodologia proposta pela Embrapa (2011). Assim, para cada bloco foram realizadas três repetições, tendo para cada repetição um par de peneiras. Então, para cada repetição, foram feitas duas titulações para as análises de carbono orgânico por peneira, multiplicando pelo número de repetições para cada bloco ( 3 vezes). Ou seja, para cada malha de peneira, foram realizadas 6 análises de carbono orgânico, que foram, posteriormente, tratadas com dados estatísticos.

Os valores obtidos nos peneiramentos foram usados para cálculo dos índices de estabilidade, utilizando equações (1, 2 e 3 ) modificadas de Kemper e Rosenau (1986), com suas respectivas siglas e referências abaixo

Diâmetro Médio Ponderado (DMP) através da equação abaixo, em que $w_{i}=$ proporção (\%) de cada classe em relação ao total; e $\mathrm{x}_{\mathrm{i}}=$ diâmetro médio das classes, expresso em $\mathrm{mm}$.

$D M P(m m)=\sum_{i=1}^{n}\left(x_{i} \cdot w_{i}\right)$

Diâmetro Médio Geométrico (DMG) através da equação abaixo, em que $w_{i}=$ proporção (\%) de cada classe em relação ao total; $\mathrm{e} \mathrm{x}_{\mathrm{i}}=$ diâmetro médio das classes, expresso em $\mathrm{mm}$.

$D M G(m m)=\exp \frac{\sum w_{i} \ln x_{i}}{\sum w_{i}}$

Índice de Estabilidade dos Agregados (IEA) através da equação abaixo, em que $\mathrm{P}=[($ peso total dos agregados - peso dos agregados $<0,25 \mathrm{~mm}$ )/peso da amostra] x 100 ; expresso em \%.

$I E A=\frac{\text { peso total dos agregados }- \text { peso dos agregados }<0,25 \mathrm{~mm}}{\text { peso da amostra seca }} \times 100$

Portanto, é possível verificar, através desta avaliação, a ocorrência da erosão hídrica, a partir dos seguintes índices de agregação do solo: DMG, que é uma estimativa do tamanho médio dos agregados que mais ocorrem no solo; DMP, que é tanto maior quanto maior for a porcentagem de

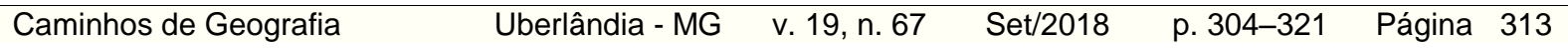


agregados grandes retidos nas peneiras com malhas maiores que $0,5 \mathrm{~mm}$; e o IEA, que é uma medida da agregação total, mas sem considerar a classe de distribuição de tamanho dos agregados, que pode refletir na resistência do solo à erosão. Logo, quanto maior a quantidade de agregados $<0,25$ mm, menor será o IEA (CASTRO FILHO et al. 1998).

\section{RESULTADOS E DISCUSSÃO \\ Infiltração da água no solo}

De acordo com os resultados obtidos no experimento de infiltração, pode-se afirmar que a floresta apresenta o maior volume de água infiltrado acumulado, seguido do cultivo de açaí e da pastagem, respectivamente (gráfico 1).

Gráfico 1: Volume de água infiltrado acumulado em diferentes usos do solo.

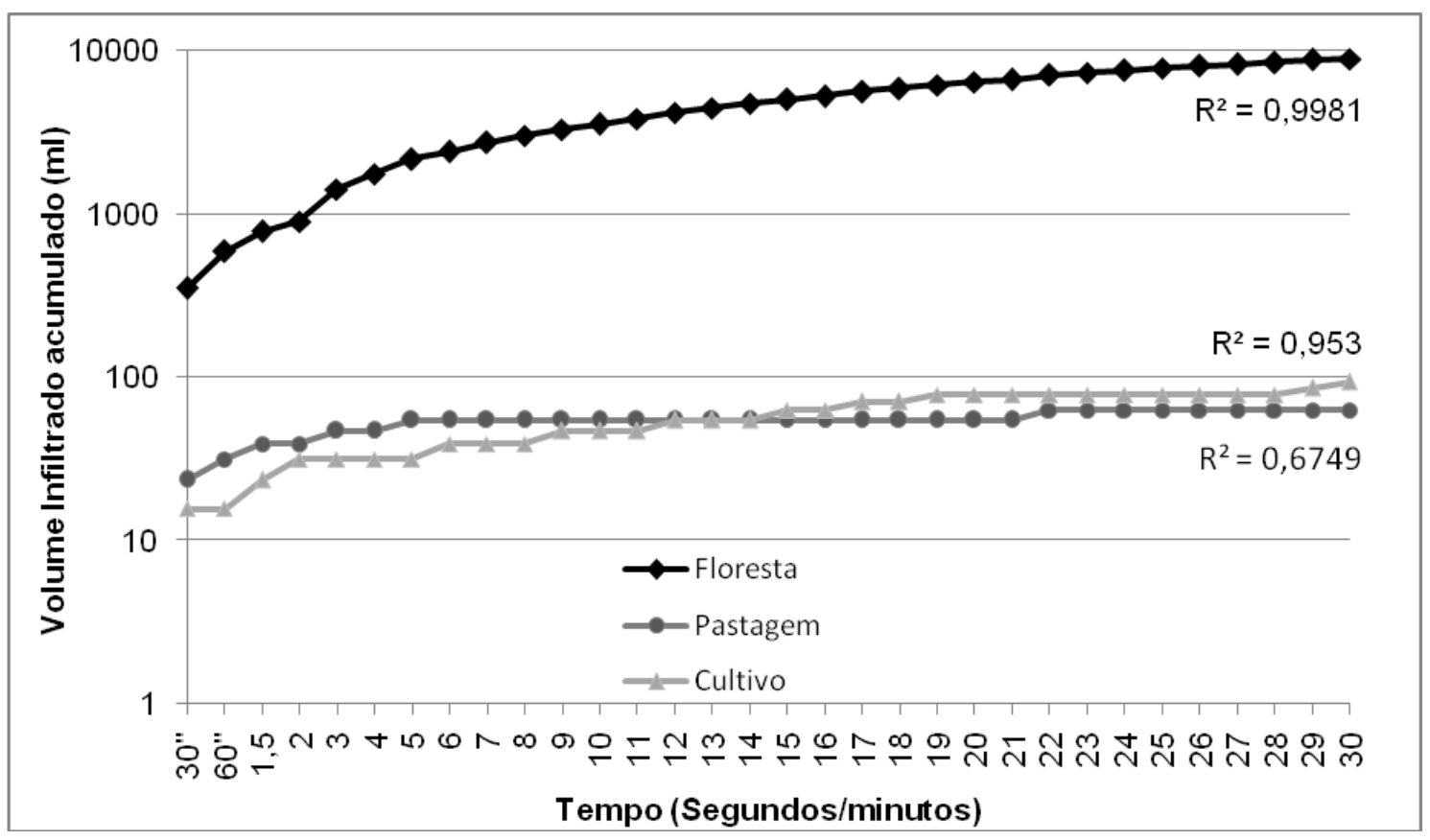

De acordo com Brizzi et al. (2017), o comportamento avaliado é derivado do tipo de uso, do manejo e das propriedades físicas alteradas (Tabela1). Segundo os autores, a pastagem, em função do pisoteio do gado, reflete uma maior densidade aparente (Dap - $1,51 \mathrm{Kg} / \mathrm{dm}^{3}$ ) e, consequentemente, menor porosidade total $(49,35 \%)$. Tais resultados refletem no menor volume de água acumulado dos três usos avaliados, o que o torna mais suscetível à erosão. A umidade do solo, antes do experimento, apresentou uma média de $30,43 \%$.

O cultivo de Açaí foi o segundo a apresentar maior volume de água acumulado infiltrado. Não obstante, não difere muito do uso do solo sob pastagem, tendo em vista que o dono da terra tem o costume de limpar e arar a terra com a enxada, deixando o solo exposto aos impactos das gotas de chuvas, resultando em um valor intermediário de densidade aparente (Dap - 1,14 $\mathrm{Kg} / \mathrm{dm}^{3}$ ). A umidade do solo antes do experimento apresentou uma média de $35,96 \%$, sendo a maior dos dois usos avaliados.

A floresta foi a que apresentou o valor mais significativo do volume de água infiltrado, influenciado pelo menor valor de densidade aparente (Dap - $1,03 \mathrm{Kg} / \mathrm{dm}^{3}$ ) e uma maior porosidade total $(58,81 \%)$. Destaca-se que o eixo " $Y$ " do gráfico 1 é apresentado em escala logarítmica, chegando a floresta a acumular praticamente 10 litros de água até o fim do experimento. A umidade do solo antes do experimento apresentou a menor média, de $21,20 \%$. 
Tais resultados estão atrelados ao acúmulo de serrapilheira na superfície do solo e sua decomposição, que funciona como regulador térmico e ajuda na formação de uma boa estrutura, o que favorece a permeabilidade da água no perfil com o aumento da energia gravitacional.

Tabela 1: Análises físicas do solo na profundidade de 0-10 cm.

\begin{tabular}{|cccccc|}
\hline Uso do solo & $\begin{array}{c}\text { Dap } \\
\left(\mathbf{K g} / \mathbf{d m}^{3}\right)\end{array}$ & \multicolumn{3}{c}{ Porosidade (\%) } & Classe Textural \\
\cline { 3 - 5 } & & Micro & Macro & Total & \\
Floresta & 1,02 & 18,52 & 40,29 & 58,81 & Franco Arenoso \\
Pastagem & 1,51 & 40,72 & 8,81 & 49,53 & Franco Arenoso \\
Cultivo & 1,14 & 21,55 & 31,17 & 52,72 & Franco Arenoso \\
\hline
\end{tabular}

Fonte: BRIZZI et al. (2017).

Estudos similares realizados por Yimer (1998), na etiópia, e Lawall et al. (2009), na região Serrana do Estado do Rio de Janeiro, mostraram uma taxa de infiltração de 2 a 15 vezes superior no uso florestal, em relação à pastagem e ao plantio de couve, respectivamente.

Veloso et al. (2011) também constataram que as maiores taxas da velocidade básica de infiltração ocorreram nos relevos de maior declividade e com vegetação preservada, sendo que as áreas agrícolas e degradadas apresentaram os menores valores de infiltração da água nos solos. Destacase que todas as áreas avaliadas apresentaram solos de classificação textural igual à apresentada para este estudo. Embora a classificação textural franco arenosa seja favorável à infiltração da água no solo, a influência do uso e do manejo na estrutura do solo dificulta a permeabilidade da água no perfil, favorecendo o escoamento superficial.

Analisando o gráfico 1 , nota-se que, nos primeiros 5 minutos, a infiltração na área de pastagem passou dos $60 \mathrm{ml}$ de volume d'água acumulado, seguido de uma constante, até os 12 minutos de experimento, quando ocorre uma pequena queda, com posterior estabilização da taxa de infiltração, novamente, em 15 minutos de experimento,. Já na área sob cultivo de açaí, há um volume acumulado mínimo de $20 \mathrm{ml}$, nos primeiros 60 segundos e máximo de $100 \mathrm{ml}$, no final do experimento. De 11 a 15 minutos de experimento, o volume de água infiltrado foi praticamente igual nos dois usos, sendo que, a partir dos 15 minutos, a área sob cultivo de açaí apresentou um valor crescente no volume de água infiltrado em relação à pastagem.

Embora o cultivo de Açaí tenha apresentado umidade antecedente de $5,5 \%$ a mais, em relação à área de pastagem, o valor de densidade aparente é inferior ao apresentado para pastagem, o que resultou em um volume acumulado superior, mas não significativo, na comparação das duas áreas agropastoris.

$\mathrm{Na}$ avaliação conjunta dos três usos, pode se afirmar que a floresta com menor umidade antecedente foi a que obteve o maior volume de água infiltrado. Podendo, nesse caso, os primeiros minutos terem sido influenciados pela poro-pressão negativa ou pela tensão da água no solo. Essas foram influenciadas, imediatamente, pelo potencial gravitacional, o qual, por sua vez, foi facilitado, majoritariamente, tanto pela boa estrutura causada pela presença de raízes (figura 9), quanto pela espessura de aproximadamente 5 centímetros de serrapilheira, assim como a maior atividade da fauna endopedônica e macroporosidade elevada (tabela 1). 
Figura 9: Identificação de raízes na superfície de uma pequena trincheira aberta na área de floresta.

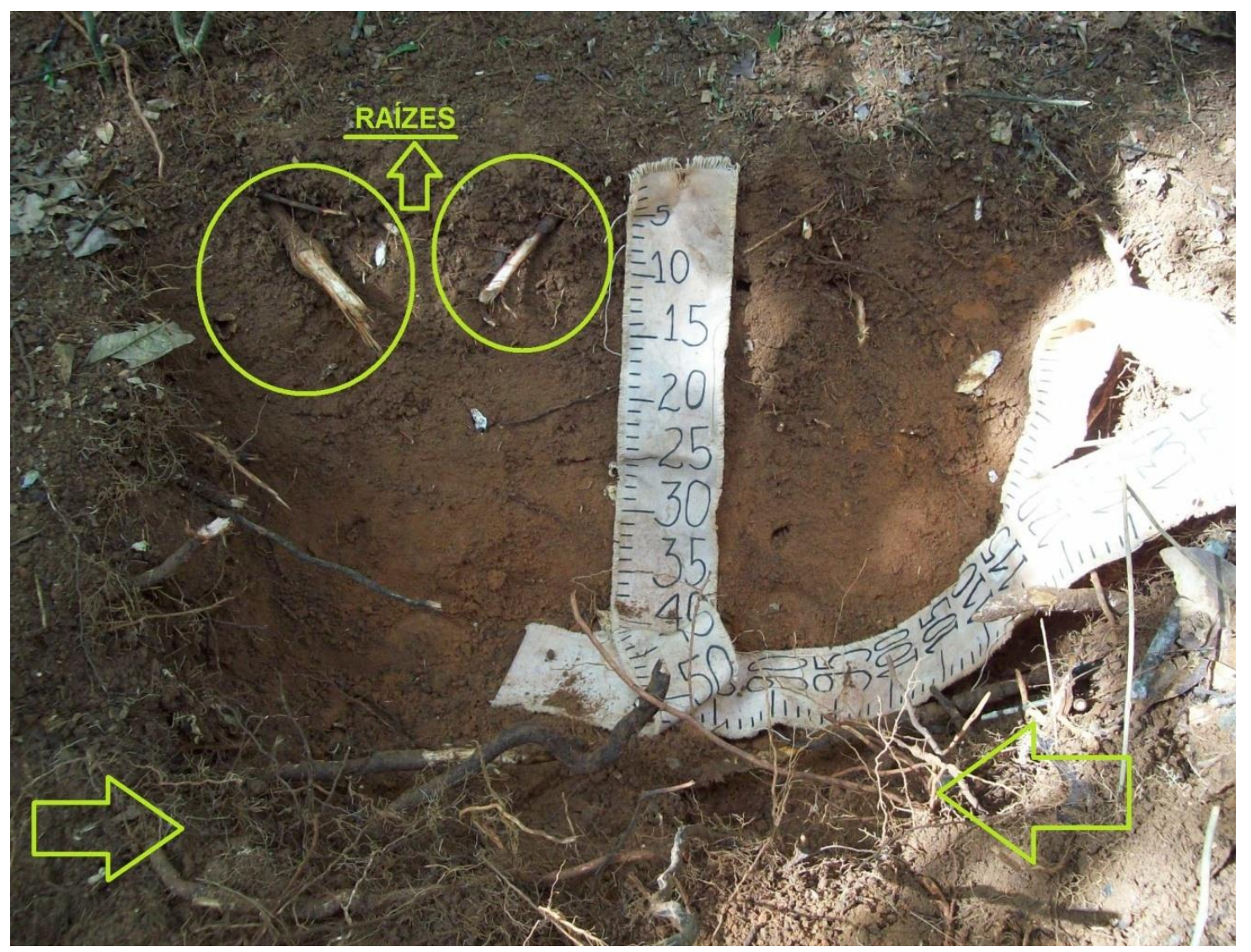

Fonte: Autor (2018).

A significativa diferença do volume acumulado nas áreas agrícolas, em relação à floresta, não pode ser explicada pelo mesmo processo. Na pastagem, a estrutura compacta do solo dificulta a infiltração e a permeabilidade. No início do experimento, a infiltração é influenciada pela poro-pressão negativa, ou tensão, mas não chegando a saturar o solo. Na área de cultivo de açaí, o processo é similar ao da pastagem, mas a estrutura granular favorecida pela aração permite um acúmulo maior de volume de água infiltrado nos 30 minutos do experimento.

Castro et al. (2012) associaram as taxas de infiltração com o escoamento superficial em mata nativa e com a pastagem degradada no Cerrado. Os autores associaram as maiores taxas de infiltração básica $(T I B)$ da água no solo à menor densidade aparente da mata nativa $\left(1,47 \mathrm{Kg} / \mathrm{dm}^{3}\right)$ e ao inverso na pastagem degradada $\left(1,55 \mathrm{Kg} / \mathrm{dm}^{3}\right)$, sendo ambos valores já considerados altos (KIEHL, 1979). Valores inferiores foram encontrados pelos autores, tendo a mata nativa apresentado $44,28 \%$ e a pastagem degradada, $41,28 \%$ de porosidade total, em relação aos valores apresentados na tabela 1 .

\section{Estabilidade dos agregados em água e Carbono Orgânico}

Para as análises de estabilidade dos agregados em água, foram avaliados o Diâmetro Médio Geométrico (DMG), Diâmetro Médio Ponderado (DMP), macro e micro agregados do solo e o Índice de Estabilidade dos Agregados (IEA) em água e sua relação com os valores de carbono orgânico de acordo com o tamanho dos agregados selecionados nas peneiras correspondentes (gráficos 2, 3 e 4).

Nas análises de estabilidade dos agregados em água, a pastagem apresentou índices de agregação mais baixos do que a floresta e o cultivo de açaí. Enquanto na pastagem, o DMG foi de 2,22 mm, na floresta, foi de 2,44 $\mathrm{mm}$ e, no cultivo de açaí, 2,70 mm. Já o DMP foi de 2,38 $\mathrm{mm}$ na pastagem, de $2,54 \mathrm{~mm}$ na floresta e de $2,71 \mathrm{~mm}$ no cultivo de açaí.

Através dos resultados apresentados, pode-se afirmar que o DMP e o DMG influenciam diretamente no IEA. Os dados de DMP foram compatíveis com as observações de Pereira e Thomaz (2014), que

\begin{tabular}{llllll}
\hline Caminhos de Geografia & Uberlândia - MG & v. 19, n. 67 & Set/2018 & p. 304-321 Página 316
\end{tabular}


apresentam valores inferiores a 2,3 $\mathrm{mm}$ como agregados mais suscetíveis à erosão. $\mathrm{O}$ atributo $\mathrm{DMG}$ é favorável a resistência dos agregados aos impactos das gotas de chuva, evitando a formação de crostas na superfície do solo e indo ao encontro das observações de Le Bissonnais (1996), que apresenta DMG maior que 2,00 mm, como os agregados mais resistentes à erosão. Assim, sustentase que os valores apresentados nos gráficos 2 e 3 indicam boa agregação do solo na profundidade avaliada, sendo que o DMP e o DMG influenciam na formação de micro a macro agregados do solo (gráfico 3).

Gráfico 2: Parâmetros de agregação sob diferentes usos do solo.

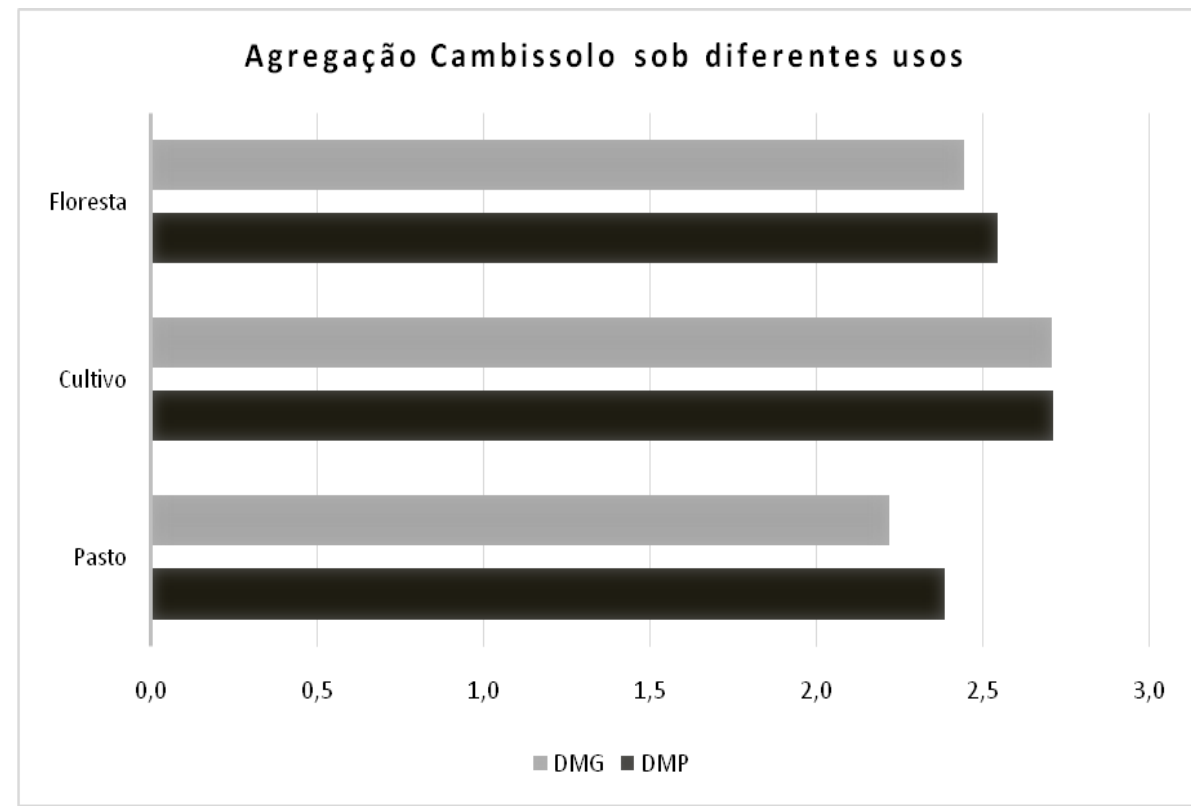

Fonte: Autor (2018)

Gráfico 3: Distribuição de macro e microagregados do solo.

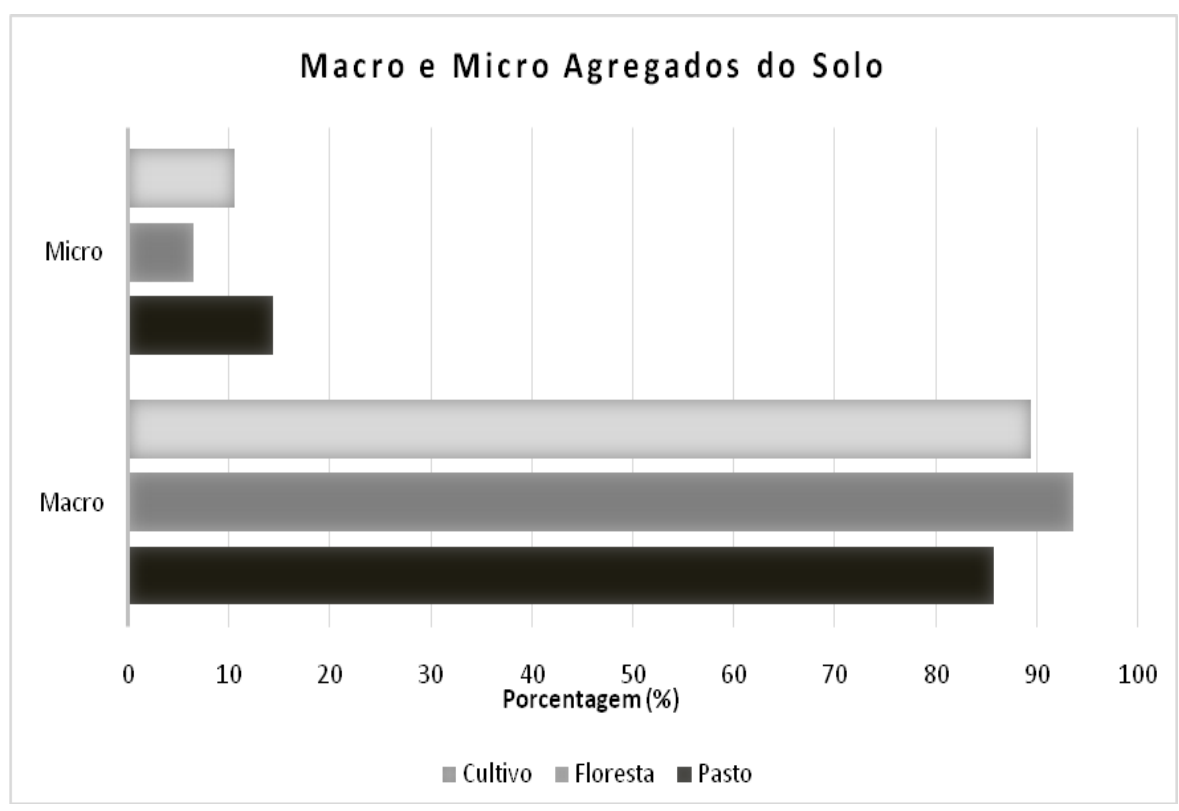

Fonte: Autor (2018) 
De acordo com o gráfico 3 , todos os usos apresentam macroagregados acima de $80 \%$, sendo esta variável maior sob o uso florestal $(93,57 \%)$, seguido do cultivo de açai $(89,45 \%)$ e da pastagem $(85,62 \%)$. Os altos valores de macroagregados e baixos valores de microagregados podem estar configurando uma maior ação das raízes e hifas de fungos presentes no horizonte superficial, possibilitando a formação de macroagregados por ação temporária desses agentes mecânicos (TISDALL e OADES, 1982).

Segundo Tisdall e Oades (1982), a formação de microagregados está relacionada com a pouca resistência dos macroagregados, quando submetidos ao umedecimento. Esses microagregados estão relacionados à porcentagem de agregados menores que $0,25 \mathrm{~mm}$ (DENEF et al., 2001), estando a formação de macroagregados acima desse valor. Logo, percebe-se que embora a floresta apresente maior porcentagem de macroagredados, os demais usos também apresentam boa agregação.

Autores como Grosbellet et al. (2011) associam a formação de macroagregados ao teor de matéria orgânica humificada, tendo em vista a sua alta capacidade de troca catiônica (CTC) em relação aos colóides minerais que compõem a estrutura do solo, formando complexos de argilas, metais polivalentes e matéria orgânica humificada na sua estrutura (EDWARDS e BREMNER, 1967). Entretanto, alguns autores tem preferido trabalhar com os dados de carbono orgânico, devido à melhor acurácia do método por titulação.

Nessa perspectiva, de acordo com Denef et al. (2001), quanto maior for a porcentagem de macroagregados no solo, maior será a estabilidade dos agregados, que, geralmente, é proporcionada pela influência do carbono orgânico no solo (CASTRO FILHO et al.,1998).

No gráfico 4, é possível observar o tipo de uso que apresenta a maior resistência do solo à erosão hídrica, a partir do índice de estabilidade dos agregados, que é influenciado pelo DMG e DMP (gráfico2), pela formação de macro e microagregados (gráfico 3) e pela sua associação com o teor de carbono orgânico.

Gráfico 4: Índice de Estabilidade dos Agregados e sua relação com o Carbono Orgânico.

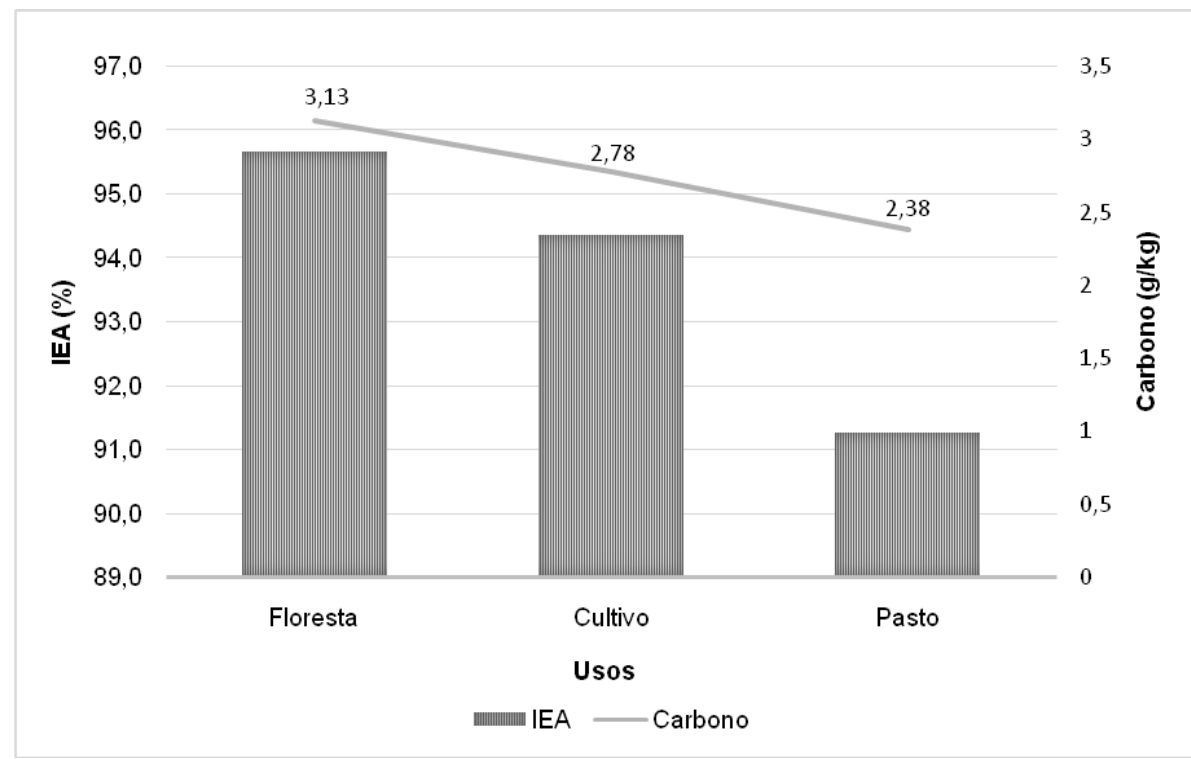

Fonte: Autor (2018)

$\mathrm{Na}$ avaliação dos dados (gráfico 1 e tabela 1), percebe-se que o uso do solo apresenta a mesma tendência de resultados favoráveis ao aumento da suscetibilidade do solo à erosão em relação ao IEA apresentado no gráfico 4, a saber,: pastagem>cultivo>floresta . Entretanto, a boa agregação do cultivo e da pastagem não resultou em um volume maior de água, ainda que tenha apresentado textura franco arenosa, como apontado por Brizzi et al. (2017). 
Autores como Mendes et al. (2011) vem utilizando os parâmetros de agregação na avaliação da erosão superficial dos solos em áreas de mata nativa e cultivo perene em regiões serranas. Os mesmos constataram uma perda de solo três vezes maior em áreas de cultivo, em relação à mata nativa, embora apresentando IEA inferior ao cultivo de banana e de olerícolas, estando estes resultados intimamente relacionados com a textura e ao próprio IEA.

\section{CONSIDERAÇÕES FINAIS}

De acordo com os resultados obtidos nessa pesquisa, pode-se concluir que:

1 - A área de floresta apresenta significativamente o maior volume de água infiltrado, seguido do cultivo de açaí e da pastagem, respectivamente.

2 - Todos os usos avaliados apresentaram valores altos de agregação do solo, refletindo em porcentagens mais altas de macroagregados.

3 - Com exceção da floresta, o resultado da agregação do solo nos demais usos, associada à compactação a que estes solos foram submetidos, não facilita a absorção de um volume maior de água.

4 - Os índices de agregação são compatíveis com os dados de infiltração da água no solo, mas não respondem o por que da redução do volume de água infiltrado no uso da pastagem e do cultivo de açaí, já que apresentaram DMP, DMG e IEA favoráveis para a resistência do solo à erosão.

Essa pesquisa se realizou com a ajuda de análises desenvolvidas em trabalhos anteriores, nos quais foram apresentados os dados de micro, macro e porosidade total e densidade aparente, citados para este estudo.

\section{AGRADECIMENTOS}

A Fundação de Amparo à Pesquisa do Estado do Rio de Janeiro (FAPERJ) e ao Instituto Federal do Rio de Janeiro (IFRJ) pelo financiamento desta pesquisa.

\section{REFERÊNCIAS}

AB'SABER, A. N. Os domínios de natureza no Brasil: Potencialidades paisagísticas. São Paulo: Ateliê Editorial, 2003. p.9-33.

BERTONI, J.; LOMBARDI NETO, F. Conservação do solo. 7ed. São Paulo: Ícone, 2010. 355p. BRADY, N. Natureza e propriedade dos solos. 7ed. Rio de Janeiro: Freitas Bastos, 1989. p.42-81, 126-159, 290322, 442-471, 572-609.

BRASIL. Levantamento de recursos naturais. Folha SF. 23/24 Rio de Janeiro/Vitória; geologia, geomorfologia, pedologia, vegetação e uso potencial da terra / Projeto RADAMBRASIL - Rio de Janeiro, 1983.

BRIZZI, R. R.; SOUZA, A, P. de.; COSTA, A. J. S. T. Influência do manejo agrícola na suscetibilidade dos solos à erosão na sub-bacia hidrográfica do rio São Romão, Nova Friburgo/RJ. Estudos Geográficos, v. 15, n. 2, p. 171-191, 2017.

CASTRO, M. A. de; CUNHA, F. F. da; LIMA, S. F. de; PAIVA NETO, V. B. de; LEITE, A. P.; MAGALHÃES, F. W.; CRUZ, G. H. M. da. Atributos físico-fídricos do solo ocupado com pastagem degradada e floresta nativa no Cerrado Sul-Mato-grossense. Geosciences and Humanities Research Medium, v. 3, n. 2, p. 498-512, 2012.

CASTRO FILHO, C. de; MUZILLI, O.; PODANOSCHI, A. L. Estabilidade dos agregados e sua relação com o teor de carbono orgânico num Latossolo Roxo Distrófico, em função de sistemas de plantio, rotações de culturas e métodos de preparo das amostras. Revista Brasileira de Ciência do Solo, v. 22, p. 527-538, 1998. https://doi.org/10.1590/S0100-06831998000300019

CASTRO FILHO, C. de; LOURENÇO, A; GUIMARÃES, M. DE. F. \& FONSECA, I. C. B. Aggregate stability under different soil management systems in a redlatosol in the state of Parana, Brazil. Soil and Tillage Research, v.65, n.1, p.45-51, 2002. https://doi.org/10.1016/S0167-1987(01)00275-6

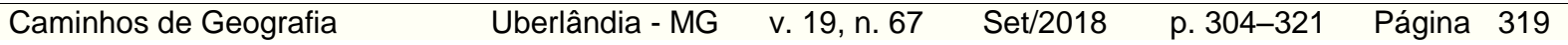


DANTAS, M. E. Geomorfologia do Estado do Rio de Janeiro. Texto explicativo do mapa geomorfológico do Estado do Rio de Janeiro. Brasília: CPRM. 2ed. 2000.

DENEF, K.; SIX, J.; PAUSTIAN, K.; MERCKX, R. Importance of macroaggregate dynamics in controlling soil carbon stabilization: short-term effects of physical disturbance induced by dry-wet cycles. Soil Biology and Biochemistry, v. 33, p. 2145-2153, 2001. https://doi.org/10.1016/S0038-0717(01)00153-5

EDWARDS, A. P.; BREMNER, J. M. Microaggregates in soils. Journal Soil Science, v.18, p.64-73. 1967. https://doi.org/10.1111/j.1365-2389.1967.tb01488.x

EMBRAPA - Empresa Brasileira de Pesquisa e Agropecuária. Disponível em: < http://www.agencia.cnptia.embrapa.br/gestor/solos_tropicais/arvore/CONTAG01_8_2212200611538.html $>$ Acesso em: 9 de maio de 2018.

Mapa de reconhecimento de baixa intensidade dos Solos do estado do Rio de Janeiro. Ministério da Agricultura, pecuária e do Abastecimento, 2003.

Manual de métodos de análise de solo. 2.Ed. Rio de Janeiro: Embrapa solos, 2011.

FORMIGA, K. T. M.; SEIBT, A. C.; CASTRO, T. Q. de.; BERNARDES, R. S. A infiltração e o escoamento superficial. In: CAMAPUM DE CARVALHO, J.; GITIRANA JUNIOR, G. de F. N.; CARVALHO, E. T. L. (Orgs). Tópicos sobre infiltração: teoria e prática aplicadas a solos tropicais. Brasília: Faculdade de Tecnologia, 2012. p.101-116.

FREITAS, M. M. de. Funcionalidade Hidrológica dos cultivos de banana e territorialidades na paisagem do Parque Municipal de Grumari-Maciço da Pedra Branca - RJ. Dissertação (Mestrado em Geografia) - Rio de Janeiro: UFRJ, 2003.

GROSBELLET, C.; VIDAL-BEAUDET, L.; CAUBEL, V. \& CHARPENTIER, S. Improvement of soil structure formation by degradation of coarse organic matter. Geoderma 162, p.27-38, 2011.

https://doi.org/10.1016/j.geoderma.2011.01.003

GUERRA, A. J. T. Processos erosivos nas encostas. In: GUERRA, A. J. T.; CUNHA, S. B. da (Orgs). Geomorfologia: uma atualização de bases e conceitos. 9ed. Rio de Janeiro: Bertrand Brasil, 2009a. p.149-197.

GUERRA, A. J. T. Processos erosivos nas encostas. In: CUNHA, S. B. da.; GUERRA, A. J. T. (Orgs). Geomorfologia: exercícios, técnicas e aplicações. 3 ed. Rio de Janeiro: Bertrand Brasil, 2009b. p.139155.

GUERRA, A. J. T. O início do Processo erosivo. In: GUERRA, A. J. T.; SILVA, A. S. da; BOTELHO, R. G. M.(Orgs). Erosão e conservação dos solos: Conceitos, temas e aplicações. 4ed. Rio de Janeiro: Bertrand Brasil, 2009c. p.1-35.

HILLEL, Daniel. Solo e água: fenômenos e princípios físicos. Porto Alegre: UFRGS, 1970. 231p.

HORTON, R. E. Erosional development of streams and their drainage basins -hydrophysical approach to quantitative morphology. Geological Society of America Bulletin, v.56 p. 275-370, 1945.

https://doi.org/10.1130/0016-7606(1945)56[275:EDOSAT]2.0.CO;2

ICMBio - Instituto Chico Mendes de Conservação da Biodiversidade. Disponível em: < http://www.icmbio.gov.br/corredordasoncas/pt/o-corredor/o-novo-codigo-florestal > Acesso em: 16 de Janeiro de 2017a.

. http://sistemas.icmbio.gov.br/simrppn/publico/rppn/RJ/ > Acesso em: 16 de Janeiro de 2017b.

INEA - Instituto Estadual do Ambiente. O estado do ambiente: Indicadores ambientais do Estado do Rio de Janeiro 2011. Rio de Janeiro: SEA; INEA, 2011. 160p.

KEMPER, W. D.; ROSENAU, R. C. Aggregate stability and size distribution. In: KLUTE, A. (Ed.) Methods of soil analysis - Part I: Physical and minerological methods. Wisconsin: Madison, 1986.p.425-442.

KIEHL, E. D. Manual de edafologia: relações solo-planta. São Paulo: Editora Agronômica Ceres, 1979.

LAWALL, S.; SANTOS, A. C. F.; SILVA, P. de F. C.; MOTA, P. de O.; FERNANDES, N. F. Modificações da Dinâmica Hidrológica do Solo em Resposta as Mudanças de uso e Cobertura: um estudo de Caso na Região Serrana do Rio de Janeiro. In: XIII Simpósio Brasileiro de Geografia Física Aplicada. Anais... Viçosa - MG, 2009. 
LE BISSONNAIS, Y. Aggregate stability and assessment of soi1 crustability and erodibility: 1 . Theory and methodology. European Journal of Soil Science, v. 47, p. 425-437, 1996.

https://doi.org/10.1111/j.1365-2389.1996.tb01843.x

LIMA, L. D. M.; SILVEIRA, P.G.; SILVA, F.F.; LOUREIRO, H. A. S. Estudo dos Processos Erosivos no Médio e Alto Curso da Bacia Hidrográfica do Rio Macaé, Macaé/RJ. Geografia. Ensino \& Pesquisa, v. 12, [s.p]. 2008.

MARTINS, J. A. Infiltração. In: Hidrologia básica. SOUSA PINTO, N. L. de.; HOLTZ, A. C. T.; MARTINS, J. A.; GOMIDE, F. L. S. (ORG). Sao Paulo: Edgard Blucher, 1978. p. 44-55.

MEDINA, H. P. Constituição física. In: MONIZ, Antônio Carlos (Org). Elementos de pedologia. São Paulo: Polígono - Editora da universidade de São Paulo, p. 1-8, 1972.

MENDES, C. A. R.; MALHLER, C. F.; ANDRADE, A. G. de. Erosão superficial em argissolo amarelo sob cultivo perene e com pousio florestal em área de relevo montanhoso. Revista Brasileira de Ciência do Solo, v.35, n.4, p.1387-1396, 2011. https://doi.org/10.1590/S0100-06832011000400033

MENDES, S. P. Identificação e avaliação da paisagem da Área de Proteção Ambiental de Macaé de Cima (RJ). Dissertação (Mestrado em Geografia) - Rio de Janeiro: UFRJ, 2010. 136p.

MYERS, N. Threatened Biotas: "Hot Spots" in Tropical Forests. The Environmentalist, V. 8, N. 3, p.187208, 1988. https://doi.org/10.1007/BF02240252

MORGAN, R. P. C. Soil erosion and conservation. 1ed. Estados Unidos: Longman Scientific Technical, 1986. 298p.

NASCIMENTO, F. J. B. do; HINGEL, R. L.; SOUZA, P. A. de; MARÇAL, M. dos S. Caracterização espaçotemporal das chuvas associadas às vazões na bacia do rio Macaé - RJ. In: IX Simpósio Brasileiro de Climatologia Geográfica - Climatologia e gestão do território. Anais... Fortaleza - CE: 2010.

NEVES, S. R. de A.; LOUREIRO, H. A. S.; GUERRA, A. J. T. Erosão dos Solos na Bacia do Rio Macaé: Os Casos das Sub-bacias do Rio das Flores e do Rio São Pedro - RJ. In: Simpósio Brasileiro de Geografia Física Aplicada. Anais... Dourados - MS: 2011.

PEREIRA, A. A.; THOMAZ, E. L. Estabilidade dos agregados em diferentes sistemas de uso e manejo no município de Reserva - PR. Revista Brasileira de Geografia Física., v.7, n.2, 378-387p. 2014.

REICHARDT, K.; TIMM, L. C. Solo, planta e atmosfera: conceitos, processos e aplicações. 2ed. Barueri, SP: Manole, 2012. p.9-50, 89-185, 243-278.

SILVA, L. F. T. C. da.; BEZERRA, J. F. R.; GUERRA, A. J. T. Implicações da mudança na cobertura vegetal em relação a erosão na sub-bacia hidrográfica do rio São Pedro - RJ. Revista Geonorte, v.1, n.6, p.1-16, 2012.

SOUSA PINTO, N. de. Águas subterrâneas. In: Hidrologia básica. SOUSA PINTO, N. L. de.; HOLTZ, A. C. T.; MARTINS, J. A.; GOMIDE, F. L. S. (ORG). Sao Paulo: Edgard Blucher, 1978. p. 67-91

TISDALL, J. M.; OADES, J. M. Organic matter and water-stable aggregates in soils. Journal Soil Science. v. 33, p. 141-163, 1982. https://doi.org/10.1111//.1365-2389.1982.tb01755.x

VELOSO, E. da C.; ROCHA JUNIOR, A. F.; LEITE, L. F. C.; BLANCO, F. F.; CARVALHO, T. T. C. B. de. Granulometria e velocidade de infiltração da água no solo em área degradada. In: II congresso Brasileiro de Pesquisas de Pinhão-Manso. Anais... Brasília: 2011.

YIMER, F., MESSING, I., et al. Effects of different land use types on infiltration capacity in a catchment in the highlands of Ethiopia. Soil Use and Management. 24 (4): 344-349, 1998.

https://doi.org/10.1111/j.1475-2743.2008.00182.x

YODER, R. E. A direct method of aggregate analysis of soils and a study of the physical nature of erosion losses. Journal American Society Agronomy. v. 28, p. 337-351. 1936.

https://doi.org/10.2134/agronj1936.00021962002800050001x

Recebido em: 25/05/2017

Aceito para publicação em: 23/05/2018 